\title{
Internacionalização do currículo: produção em organismos multilaterais
}

\author{
Internationalization of the curriculum: production in multilateral \\ organizations
}

\begin{abstract}
Internacionalización del plan de estudios: producción en organismos multilaterales
\end{abstract}

\begin{abstract}
Marília Costa Morosini ${ }^{1}$
Pontifícia Universidade Católica do Rio Grande do Sul, Professora titular no Programa de Pós-graduação em Educação, Coordenadora do Centro de Estudos em Educação Superior
\end{abstract}

Resumo: A internacionalização da educação superior vem se expandindo no contexto da globalização e da Sociedade do Conhecimento. Recentemente, organismos multilaterais, capitaneados pela OCDE, passam a propor outras formas para a internacionalização, como a do currículo. O artigo tem como foco a Internacionalização do Currículo ( $\mathrm{IoC}$ ) e a interferência de organismos multilaterais, via produção de textos, nesse processo. É apontada a complexidade dessa concepção que se estende desde a formação profissional para o mercado globalizado até a formação do cidadão global pela Unesco. Para fundamentar as análises são utilizados princípios de estado de conhecimento tendo como fonte a bibliografia internacional oriunda de organismos multilaterais e/ou decorrentes.

Palavras-chave: Internacionalização da Educação Superior. Internacionalização do currículo. Organismos multilaterais. Educação Superior.

Abstract: The internationalization of higher education has been expanding in the context of globalization and the Knowledge Society. Recently, multilateral organizations, led by the OECD, are proposing other forms of internationalization such as the curriculum. The article focuses on Internationalization of the Curriculum - IoC and the interference of multilateral organizations through the production of texts in this process. It is pointed out the complexity of conception that extends from professional training to the globalized market to the formation of the global citizen (UNESCO).

1 Pós-doutora no LILLAS pela Universidade do Texas; Doutorado em Educação pela Universidade Federal do Rio Grande do Sul. 
To base the analyzes are used principles of knowledge state having as source international bibliography from multilateral organizations and / or derived.

Keywords: Higher Education internationalization. Internationalization of the curriculum. Multilateral organizations. Higher Education.

Resumen: La internacionalización de la educación superior se ha ido expandiendo en el contexto de la globalización y la sociedad del conocimiento. Las organizaciones multilaterales, encabezados por la OCDE, van a proponer otras formas de internacionalización, como el plan de estudios. El artículo se centra en la internacionalización del Plan de estudios - IoC y la interferencia de las organizaciones multilaterales, a través de la producción de textos en el proceso. Se pone de relieve la complejidad del concepto que se extiende desde la formación profesional para el mercado global hasta la formación del ciudadano global (UNESCO). El apoyo de análisis son los principios del estado de conocimiento tiendo como recurso la literatura internacional provenientes de organismos multilaterales y / o decurrentes.

Palabras clave: Internacionalización de la Educación Superior. Internacionalización de plan de estudios. Organizaciones multilaterales. Educación Superior.

\section{INTRODUÇÃO}

A internacionalização da educação superior vem se expandindo (EGRONPOLAK; HUDSON, 2014) de forma acentuada no contexto da globalização e da Sociedade do Conhecimento (UNITED NATIONS, 2005). A partir do final do século $\mathrm{XX}$, direcionou-se à função universitária do ensino e passou a utilizar, como critério para a circulação de títulos, diplomas e constitutivos, a qualidade (MOROSINI, 2014). Nesse sentido, um complexo arcabouço para garantir a qualidade é disseminado e atinge, não apenas a esfera internacional (DALE, 2011), mas a regional, a nacional e a institucional (BALL, 2010).

A internacionalização é ligada e, muitas vezes, confundida, com cooperação internacional e, frequentemente com intercâmbios de professores e/ou estudantes. No global Sul predomina o conceito relacionado à mobilidade, seja a out - sair do país de origem e/ou a in - receber pessoas no país para realizar estudos (MOROSINI; DALLA CORTE; ANSELMO, 2017).

A expansão da Internacionalização da educação superior está ligada aos movimentos que originaram a criação e a implementação de um espaço europeu de 
ensino superior no quadro do processo de Bolonha ${ }^{2}$ que, por sua vez, reforça o papel das universidades na sociedade e na economia do conhecimento na Europa e destaca a importância da mobilidade acadêmica para a consolidação desse espaço. Em 2000, a European Association on International Education (EAIE) registrava baixos números da mobilidade estudantil na União Europeia (era previsto que 10\% de estudantes de cada país integrante da EU teria uma experiência de mobilidade durante a sua formação). Após 10 anos da implantação de projetos como o Sócrates, o Erasmus e o Tempus, ${ }^{3}$ a preocupação com a formação de um cidadão europeu apoiado na cooperação internacional tornou-se prioridade. Entre as questões levantadas destaca-se: como desenvolver uma educação com dimensão europeia e internacional para os estudantes com não-mobilidade? (CROWTHER et al., 2000).

Para responder a essa questão e a outras relacionadas, dois conceitos se constituíram como fundamentais: a) internacionalização at home (IaH) - qualquer atividade acadêmica relacionada internacionalmente com exceção da mobilidade estudantil e docente (CROWTHER et al., 2000, p. 8); b) internacionalização do currículo (IoC) - desenvolvimento de experiências internacionalizadas para todos os estudantes por meio de iniciativas curriculares formais e/ou informais (LEASK, 2009, p. 21). A IoC pode incluir tanto atividades locais quanto mobilidade docente e estudantil. O termo IaH pode abarcar as funções universitárias, desde as tradicionais, como o ensino, a pesquisa e a extensão, como também as funções contemporâneas e complexas, com destaque à perspectiva da inovação e, especificamente, à inserção das relações universidade-empresa. O termo IoC está focado na função ensino e é orientado pelos organismos multilaterais e outras fontes influenciadas pelos organismos internacionais (OIs).

Assim, este artigo tem como foco a internacionalização do currículo e a interferência de organismos multilaterais, via produção de textos. Para fundamentar as

\footnotetext{
2 A Comissão das Comunidades Europeias estabelece, em 2003, que o crescimento da sociedade depende da produção de maiores conhecimentos, da sua transmissão por meio da educação e formação, da sua divulgação pelas tecnologias de informação e comunicação e da sua utilização em novos serviços ou processos industriais (MOROSINI, 2006, p. 122).

3 Sócrates - programa de ação comunitária da comissão europeia para a cooperação transnacional na educação, em Estados-Membros da UE e outros; Eramus - ação do Sócrates, criada em 1987, para mobilidade de estudantes e docentes do ensino superior entre os estados da UE e estados associados; Erasmus Mundus - lançado em 2004, concede bolsas de mestrado para estudantes de todo o mundo em universidades europeias; Tempus - programa da UE que apoia a modernização do ensino superior nos países parceiros da Europa Oriental, da Ásia Central, nos Balcãs Ocidentais e da Região Mediterrânica, por meio de projetos de cooperação universitária.
} 
análises realizadas são utilizados princípios de construção de estado de conhecimento (MOROSINI, 2015), apoiados em bibliografia internacional produzida por organismos multilaterais e/ou decorrentes.

\section{CONCEPÇÕES DE INTERNACIONALIZAÇÃO DO CURRÍCULO}

No exame da bibliografia sobre IoC é apontada a complexidade dessa concepção, bem como possíveis estratégias de implantação. Em grandes linhas, foram identificadas concepções de IoC que se estendem desde a internacionalização voltada à formação profissional, com foco no atendimento às exigências de um mercado globalizado, até aquela relacionada à noção de cidadão global, via Educação para a Cidadania Mundial pressuposta pela Organização das Nações Unidas para a Educação, a Ciência e a Cultura (UNESCO, 2015a).

Nas primeiras definições mapeadas, a concepção de currículo internacionalizado está voltada à formação profissional, tanto na perspectiva profissional quanto na social. A Organização para a Cooperação e Desenvolvimento Econômico (OECD) entende a IoC como um currículo com orientação internacional, considerando seu conteúdo e forma e preparação profissional e social dos estudantes na perspectiva de contexto internacional e multicultural (VAN DER WENDE, 1996). Tal concepção tem como base um modelo de universidade relacionado à formação de um indivíduo para o século XXI, com o predomínio de princípios para o mercado globalizado. É o denominado profissional flexível na sociedade do conhecimento decorrente de projeto comandado pela comissão europeia (REFLEX, 2011) e replicado na América Latina, com o título de Proflex.

Ainda em 1996, a OECD, por meio do Centre for Educational Research and Innovation (CERI), propõe uma tipologia para os currículos internacionalizados: currículo com conteúdo internacional, como por exemplo, relações internacionais, direito europeu; currículo com conteúdo tradicional/original fundamentado em uma perspectiva comparativa internacional, a exemplo da educação internacional comparada; currículo que prepara os estudantes para profissões internacionais, como a administração de negócios internacionais; currículo em língua ou linguística estrangeira que explicita questões de comunicação cross-cultural e oferece capacitação em habilidades interculturais; currículo com programas interdisciplinares, como estudos regionais e/ou por área, a exemplo dos europeus, escandinavos, estudos asiáticos; 
currículo orientado para a certificação internacional de qualificações profissionais; currículo direcionado para a dupla diplomação ou conjunta; currículo com módulos obrigatórios em instituições do exterior e por professores locais; e currículo com conteúdo direcionado para estudantes estrangeiros.

Nessa mesma linha de pensamento, a European Association on International Education (EAIE), em trabalho encomendado, amplia a concepção da OECD, abarcando a formação emocional e as habilidades interculturais. Assim, a IoC é entendida como: "Um currículo que oferece conhecimentos e habilidades internacionais e interculturais, com objetivo de preparar estudantes para a performance profissional, social e emocional em um contexto internacional e multicultural." (NILSSON, 2000, p. 18).

Mais recentemente, Clifford (2013) consolida o entendimento da IoC na perspectiva intercultural. Defende que um currículo pode ser classificado como internacional se incluir uma perspectiva global ou se desenvolver capacidades crosscultural ou, ainda, se constituir fonte de novas ideias para a internacionalização considerando os seguintes aspectos: internacionalização do conteúdo do curso, ${ }^{4}$ internacionalização das atividades de ensino e aprendizagem, internacionalização da avaliação e internacionalização on-line. ${ }^{5}$ A autora sintetiza que um currículo internacionalizado pode ter alguns componentes comuns: perspectivas globais, comunicação intercultural e formação do cidadão responsável socialmente. Assim, a implantação da IoC pode se transformar em educação focada exclusivamente no mercado ou pode voltar-se a uma aprendizagem intercultural, e/ou à construção de um cidadão global. Entre essas posturas variadas outras são encontradas e, mesmo essas, não se configuram como tipo ideal weberiano, ou seja, não são currículos de fundamentação epistemológica puros e a imbricação entre elas pode ocorrer.

\footnotetext{
4 Para Clifford (2013) a IoC deve incluir: estudos de caso, projetos e variedade de culturas diferentes; instâncias reais ou simuladas de negociação e comunicação intercultural; referência específica às questões interculturais na prática profissional; investigação de práticas profissionais; referência específica ao conteúdo contemporâneo internacional e local; abordar questões como justiça social, equidade, direitos humanos e questões sociais e econômicas relacionadas; questões ambientais globais e críticas; questões éticas na globalização; práticas internacionais atuais; informação de como o conhecimento pode ser construído de forma diferente de cultura para cultura na área de disciplina; livros ou artigos internacionais recentemente publicados.

5 A internacionalização on-line pode se efetivar por meio de: simulações on-line contemplando culturas diferentes; grupos de discussão para explicar a própria perspectiva cultural e contrastar a sua com as perspectivas culturais de outros membros do grupo; pesquisa sobre tradições profissionais; grupos de tutoria on-line constituídos por estudantes de diferentes origens culturais.
} 
Os fundamentos dessas concepções podem refletir relações com uma educação disciplinar e/ou com uma educação mais ampla e interdisciplinar. Via de regra, os currículos giram em torno de disciplinas. Essas, com uma larga tradição secular, têm foco na profissionalização e são difíceis de serem alteradas. Uma segunda concepção tem uma visão mais abrangente e está relacionada à formação geral. Entre essas concepções, também, estão imbricadas a competição no mundo profissional e a construção de uma perspectiva de inclusão do outro, com respeito à raça, gênero, situação econômica e desenvolvimento social (LEASK, 2009). Nessa perspectiva, o direcionamento internacional da IoC pode ser visualizado no Diagrama a seguir:

Diagrama 1 - Quadro conceitual da Internacionalização do Currículo - IoC

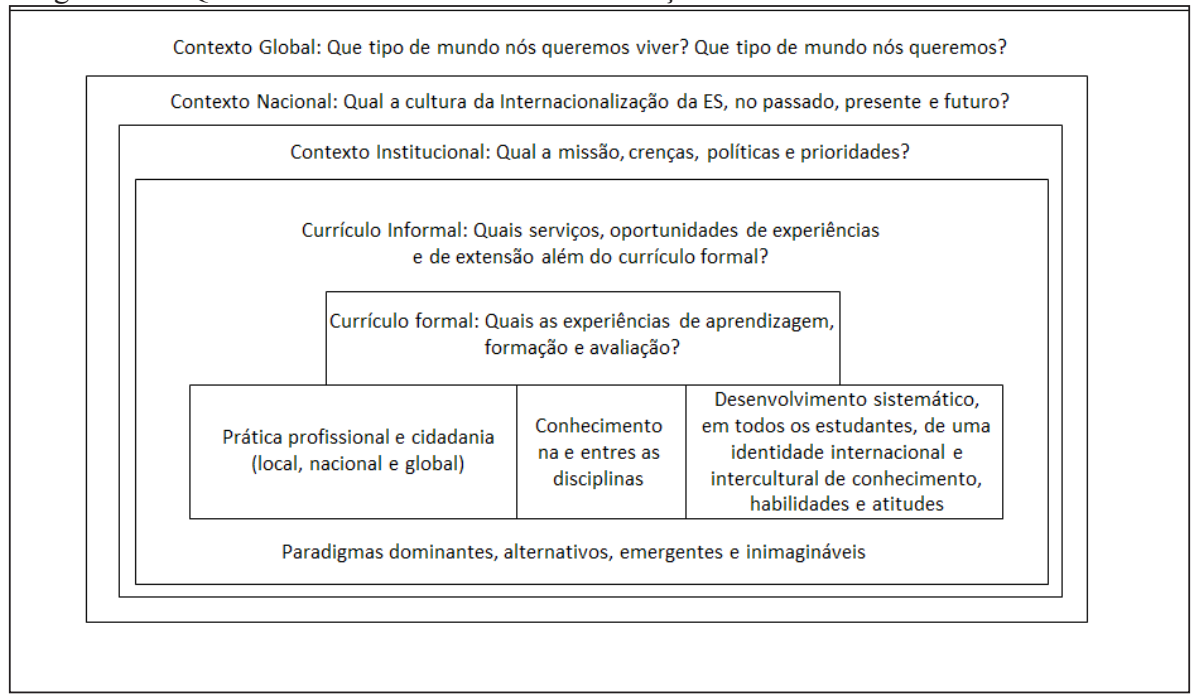

Fonte: Leask (2015, p. 27).

$\mathrm{Na}$ análise do escopo da IoC, o centro é ocupado pelos currículos formal, informal e oculto, aqui compreendidos como aqueles que seguem normas, valores e crenças subjacentes estruturadas nas instituições educativas. Leask (2015) identifica três níveis de interferência nas decisões curriculares - o nível global, o nacional e o da instituição. Essa imbricação é reforçada em pesquisa da OCED/IMHE (HERNAR, 2010), que constatou que a qualidade do ensino é decorrente da sinergia entre dois grupos de fatores: os externos às instituições, tanto nacionais quanto internacionais, e os internos de cada instituição. 
O Diagrama 1 permite reconhecer a importância do conhecimento nas disciplinas e entre as disciplinas com a formação para a profissão e para a cidadania em nível local, nacional e global e para a formação de uma identidade internacional. Com base nesse escopo, a presença de paradigmas - dominantes, alternativos, emergentes e não imaginados - é registrada.

Nilsson (2000) constata que a maioria dos currículos internacionalizados se relacionam ao mercado profissional em decorrência da forte dominância dos campos disciplinares e de seus objetivos. Cita, como exemplo, os currículos de negócios e da área econômica e propõe que os currículos internacionalizados estejam voltados para:

Objetivos cognitivos para incrementar competências internacionais nos estudantes (línguas estrangeiras, estudos regionais e por área, humanidades e conteúdo como direito e negócios internacionais).

Atitude-relacionada aos objetivos para o incremento de competências interculturais (mente aberta, compreensão e respeito por outras pessoas e suas culturas, valores e formas de viver; compreensão da natureza do racismo, etc.).

Habilidades cognitivas: proficiência em língua, habilidades de negócios internacionais, conhecimento da cultura e da história de outro país, etc.

Objetivos relacionados com competencias interculturais dos estudantes. Mais difícil de especificar em termos de conteúdo e de avaliação, mas podem ser apontados: estudos de língua estrangeiras, e questões internacionais e de outros países. (NILSSON, 2000, p. 21).

\section{CURRÍCULO E COMPETÊNCIAS INTERCULTURAIS}

Acompanhando o desenvolvimento da importância da internacionalização da educação superior e, mais especificamente, de currículos internacionalizados podemos constatar estudos sobre as competências interculturais. No Diagrama 2, Leask (2015, p. 65) propõe o cruzamento de conhecimentos, atitudes e habilidades com os níveis de consciência, compreensão e autonomia. Nessa lógica, a IoC prioriza formar um indivíduo que, em um primeiro estágio, o da consciência, se apossa de outras culturas por meio do conhecimento de suas normas, valores e experiências e consegue aplicar na sua rotina. Em um segundo estágio, o da compreensão, afirma que o indivíduo analisa como a diversidade influencia a interação entre sujeitos e busque implementar comportamentos para os diferentes contextos. E, finalmente, em um terceiro nível, o da autonomia, que se fundamenta na identificação e na compreensão 
da diversidade cultural diversa e proponha uma interação respeitosa com essa cultura para possibilitar o enfrentamento de condições de incerteza e de desenvolvimento profissional.

Diagrama 2 - Desenvolvimento de competências interculturais

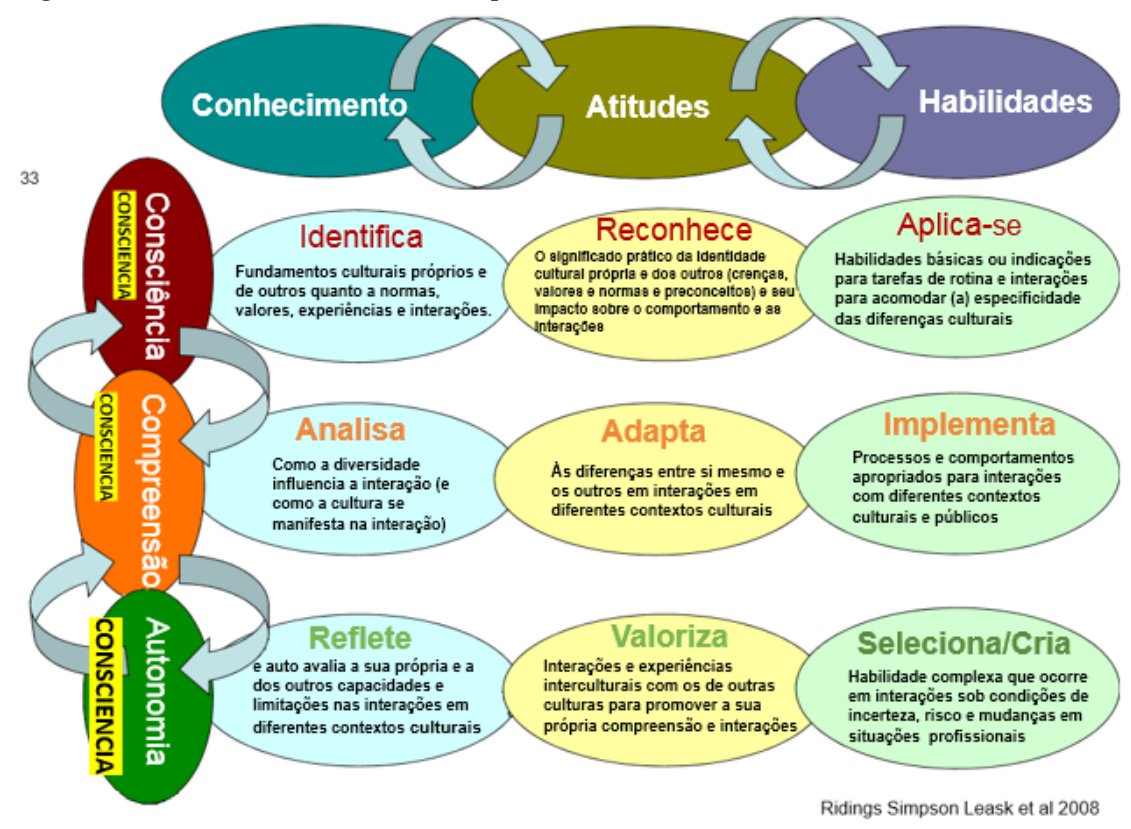

Fonte: Leask (2015, p. 65).

As competências interculturais são conceituadas como processo de aprendizagem dinâmico, contínuo, interativo e auto-reflexivo que transforma atitudes, habilidades e conhecimentos para uma adequada e eficaz comunicação e interação entre culturas (FREEMAN et al., 2008). Constituem-se em um conjunto de habilidades e características cognitivas, afetivas e comportamentais que suportam a interação eficaz e adequada em uma variedade de contextos culturais (BENNETT, 2008).

O foco sobre as competências interculturais se consolida, no momento atual, e inúmeras questões são pesquisadas. Uma delas é o processo de incorporação das competências interculturais. É identificada uma relação entre as diferentes fases constitutivas das competências interculturais (consciência, compreensão e autonomia), e aspectos constitutivos do corpus do currículo e de sua implantação institucional. São 
elas: comunidades de prática e lideranças; currículo propriamente dito, políticas e procedimentos; e recursos, ferramentas e banco de dados (FREEMAN et al., 2008).

Um outro grupo de pesquisas tem como foco o perfil de professores e estudantes de uma classe universitária internacional (TEEKENS, 2000). Nessa proposição, a IoC implica possuir padrões acadêmicos bons, pois é necessário sentir-se seguro na sua disciplina para poder trilhar outros caminhos; ter bom domínio de metodologias da aprendizagem e do ensino, além do domínio da língua materna, colocando suficiente atenção nas diferenças individuais; desenvolver a sua sensibilidade (consciência) cultural, procurando evitar estereótipos e respeitar as diferenças do grupo; reconhecer a variedade de estilos de ensino e de aprendizagem que condicionaram pessoas em diferentes tradições educativas, tanto via educação formal quanto informal; utilizar multimídia de forma integrada no processo de comunicação de ensino e de aprendizagem para melhorar a integração internacional; considerar que as qualificações profissionais, reconhecimento de diplomas e estágio são organizados e valorizados de forma diferente em diferentes países.

Junto às políticas de ensino, foram construídas assessorias/consultorias para o desenvolvimento da qualidade do professor internacional. Uma delas, a Higher Education Academy (HEA), situada no Reino Unido, tem como proposta proporcionar aos professores oportunidades de desenvolvimento profissional e desenvolvimento do ensino, por meio de:

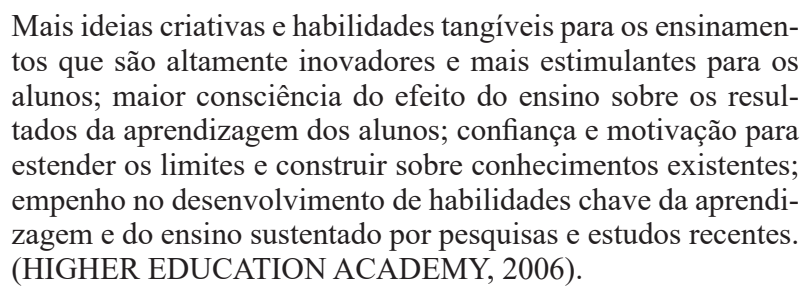

A HEA cita como exemplo de metodologia para uma aula para o estudante do século XXI; ministrar palestra; fazer feedback eficaz; propor ensino para a aprendizagem reflexiva em um ambiente multi-cultural, com apoio em ensino com inteligência emocional; criação de ambientes on-line produtivos para a aprendizagem e ensino; observar o ensino e aprendizagem; criar ambientes de sala de aula produtivos; aprimorar ensino em pequenos grupos; avaliação da/para a aprendizagem baseada em resultados; propor e implementar um currículo atualizado; ensino de métodos 
de pesquisa; ensino para a empregabilidade; e acompanhamento da experiência do estudante.

No processo de internacionalização do currículo, vem ocupando espaço uma concepção, de caráter mais amplo, que se afasta da formação para atendimento ao mercado globalizado e postula a construção de uma formação mais igualitária e solidária - a cidadania global. Entre os seguidores dessa concepção, a Unesco (2015a), como organismo multilateral, tem se distinguido. Entre as suas produções, destaca-se a Global Citizenship Education - Preparing learners for the challenges of the 21st century. Por essa concepção, é proposta a Educação para a Cidadania Mundial/Global $(\mathrm{ECM} / \mathrm{G})$ que objetiva a construção de um cidadão crítico e engajado politicamente; com pensamento globalizado e maior consciência cultural, social e ética; e com melhor preparo para um engajamento acadêmico e prático de enfrentamento dos desafios chave da sociedade.

Essa concepção reflete uma trajetória que está imbricada aos Objetivos de Desenvolvimento Sustentável e que estabelece até 2030:

[...] garantir que todos os alunos adquiram conhecimentos e habilidades necessárias para promover o desenvolvimento sustentável, inclusive, entre outros, por meio da educação para o desenvolvimento sustentável e estilos de vida sustentáveis, direitos humanos, igualdade de gênero, promoção de uma cultura de paz e não violência, cidadania global e valorização da diversidade cultural e da contribuição da cultura para o desenvolvimento sustentável. (UNESCO, 2016, p. 21).

A ECM (Diagrama 3) está centrada no aluno; a educação e’ holística e fomenta a consciência sobre problemas, preocupações e responsabilidades coletivas a nível local; alimenta o diálogo e a aprendizagem respeitosa; reconhecem as normas culturais, as políticas nacionais e os marcos internacionais que tem efeito na formação de valores; fomentam o pensamento crítico, a criatividade e a autonomia, e que recorram a busca de soluções; e que fortaleçam a resistência e competências de ação. 
Diagrama 3 - Princípios da Educação para a Cidadania Mundial

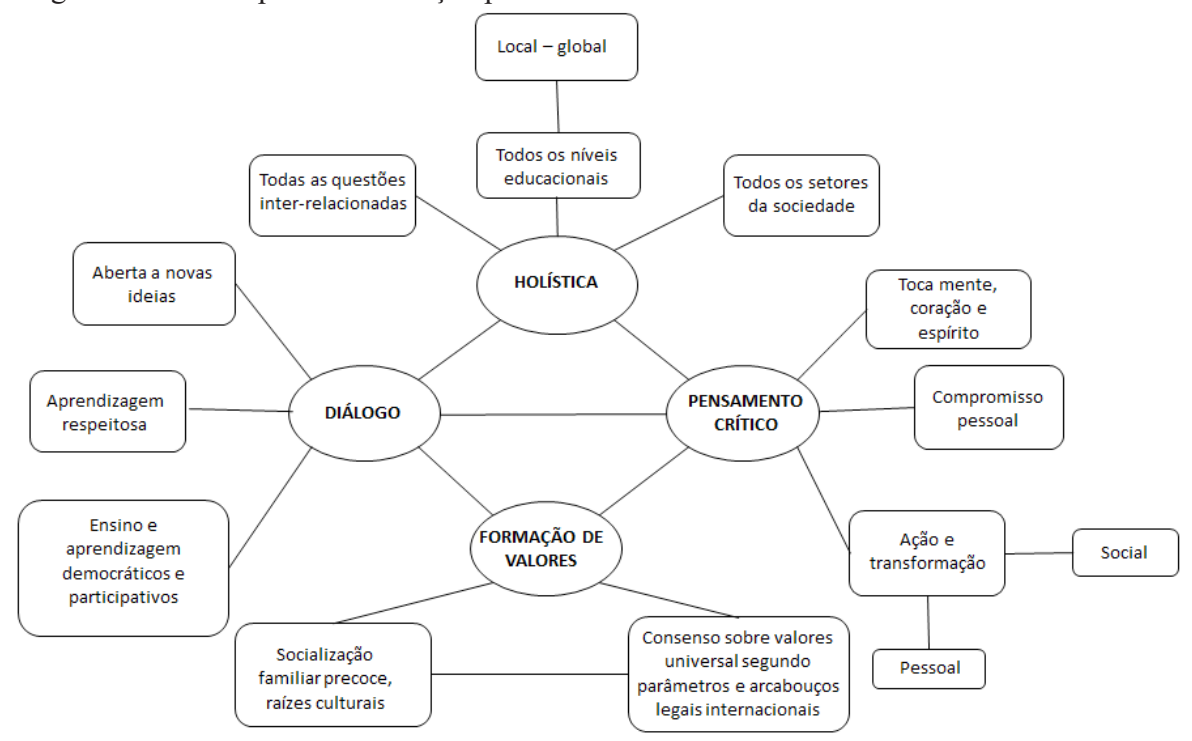

Fonte: Unesco (2015, p. 22).

A ECM apresenta pontos comuns (UNESCO, 2015), apesar de possibilitar autonomia para sua implantação, dependente do país e da instituição. São eles: uma atitude apoiada em entendimento de múltiplos níveis de identidade; um profundo conhecimento de questões globais e valores universais; habilidades cognitivas para pensar de forma crítica, sistêmica e criativa; habilidades não cognitivas, incluindo habilidades sociais e capacidades comportamentais para agir de forma colaborativa e responsável.

Para clarificar a implantação da concepção da ECM em currículos, estão sendo realizadas pesquisas e postuladas proposições de indicadores de identidade e consciência global. O Quadro 1 (UNESCO, 2015) identifica resultados de 10 anos de investigação com estudantes da África, do ensino médio e superior, com o objetivo de formar líderes socialmente responsáveis.

O estudo, tendo como cerne o estudante, identificou três eixos de indicadores relacionados entre si: o primeiro deles referido à compreensão da relação global - local e as possíveis interferências entre esses níveis; o segundo a presença, no arcabouço ético, da sensibilidade global; e o terceiro, ao registro de experiências com orientação global. 
Quadro 1 - Indicadores de identidade e consciência global, Unesco

\begin{tabular}{|c|c|c|}
\hline $\begin{array}{l}\text { Aluno interpreta con- } \\
\text { texto local inserido no } \\
\text { contexto global: }\end{array}$ & $\begin{array}{l}\text { Arcabouço ético do aluno incorpora } \\
\text { sensibilidade global: }\end{array}$ & $\begin{array}{c}\text { Experiência vivida pelo } \\
\text { aluno incorpora orienta- } \\
\text { ção global: }\end{array}$ \\
\hline $\begin{array}{l}\text { Compreende que ações } \\
\text { locais podem ter conse- } \\
\text { quências globais. }\end{array}$ & $\begin{array}{l}\text { Coloca as suas obrigações (e as de } \\
\text { terceiros) com a humanidade no ex- } \\
\text { tremo de um espectro que ultrapassa } \\
\text { o grupo interno, com intensidade de } \\
\text { efeito relativamente alta. } \\
\text { Compreende e expressa atitudes } \\
\text { positivas com relação a diferenças } \\
\text { de gênero, cultura, origens, sexuali- } \\
\text { dade, etc. }\end{array}$ & $\begin{array}{l}\text { Escolhe engajar-se em } \\
\text { atividades curriculares } \\
\text { e extracurriculares sob } \\
\text { formas que incorporam } \\
\text { orientações éticas "pró- } \\
\text {-cidadania global". }\end{array}$ \\
\hline $\begin{array}{l}\text { Compreende que forças } \\
\text { globais podem ser ex- } \\
\text { pressas localmente. }\end{array}$ & 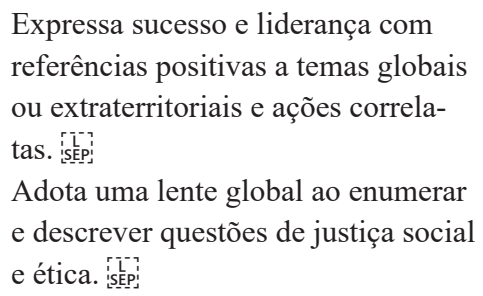 & $\begin{array}{l}\text { Incorpora de forma autô- } \\
\text { noma um enfoque global } \\
\text { implícito/ explícito em } \\
\text { atividades curriculares e } \\
\text { extracurriculares. }\end{array}$ \\
\hline $\begin{array}{l}\text { Compreende que o } \\
\text { contexto global media a } \\
\text { amplitude de escolha e } \\
\text { o impacto provável de } \\
\text { ações locais. }\end{array}$ & & $\begin{array}{l}\text { Envolve-se em ações } \\
\text { coletivas sobre questões } \\
\text { globais. }\end{array}$ \\
\hline
\end{tabular}

Fonte: Unesco (2015, p. 35).

A concepção de IoC voltada à cidadania global via Educação para a Cidadania Mundial/Global (ECM/G) traz consigo fortes tensões identificadas pela própria Unesco (2015), na confrontação entre a formação individual para o mercado de trabalho global e a formação social. Logo,

[...] a ECG propõe competitividade e solidariedade como elementos cruciais da cidadania global. [...] caso a competitividade seja encorajada como uma característica da cidadania global, inspiraremos inovação, criatividade e impulsionaremos a busca por soluções para os desafios interconectados de nosso mundo atual. Essa é uma visão nova da competição que promove a construção da capacidade de alunos para sobreviver, prosperar e melhorar o mundo em que vivemos. (UNESCO, 2015, p. 18).

Assim, é possível sintetizar as concepções de IoC entre um modelo curricular para a formação profissional do século XXI, que prevê a formação em 
quatro principais áreas: expertise profissional, flexibilidade funcional, administração do conhecimento e da inovação e mobilização de recursos humanos; e a formação do cidadão global, que se guia por princípios de solidariedade e respeito à diversidade, não esquecendo a formação profissional. É importante apontar que podem ser ainda registradas inúmeras outras formas de materialização.

\section{ALGUMAS CONSIDERAÇÕES}

A internacionalização da educação superior, via currículo, vem se fortificando neste século e aponta para uma tendência de crescimento ainda maior. Nessa trajetória o que se destaca é a complexidade do conceito de IoC e a necessidade de reflexão sobre os paradigmas que o sustentam. A concepção de IoC não está clara, da mesma forma que a concepção de internacionalização da educação superior também não. A Internacionalização da educação superior estende-se desde a mobilidade, que é a concepção mais usual, até a produção em redes, e, mais recentemente, estende-se a Internacionalização at home (IaH).

A IoC implica, da mesma forma, na mobilidade, mas tem um caráter mais abrangente e pode proporcionar aos estudantes não mobilidade uma experiência similar à daqueles que tiveram a oportunidade de uma vivência acadêmica no exterior. Outro ponto a considerar quando da análise da bibliografia é o foco da IoC. Ela pode estar dirigida à formação disciplinar e profissional com atendimento a aspectos profissionais, propriamente ditos, emocionais, sociais e interculturais; e também, pode ter um caráter mais amplo de formação para a cidadania global. Enfim, são posições em construção transversadas por tensões que refletem, em última análise, os paradigmas de entendimento da sociedade. Via de regra, os estudos em países desenvolvidos buscam um aprofundamento na IoC com formação e competitividade em um mundo globalizado e os países emergentes, com um grande gap entre as classes sociais, batalham por implantar/consolidar um desenvolvimento curricular para esse mundo globalizado, além de princípios de atendimento a diversidade.

É importante retomar a assertiva que afirma que as políticas globais adquirem interferências dos contextos particulares. Logo, tanto as interferências dos organismos multilaterais apontadas neste texto, quanto a internacionalização da educação superior se enfrentam com a realidade local. E, no Brasil, nos encontramos frente a grandes desafios para a implantação do Plano Nacional de Educação (PNE) 
(2014 - 2014), que determina, entre outras medidas: elevar a taxa bruta e líquida de matrícula na educação superior, bem como elevar a formação de mestres e doutores no corpo docente e na titulação anual, na pós-graduação stricto sensu; consolidar programas, projetos e ações que objetivem a internacionalização da pesquisa e da pósgraduação brasileira, incentivando a atuação em rede e o fortalecimento de grupos de pesquisa; promover o intercâmbio científico e tecnológico, nacional e internacional, entre as instituições de ensino, pesquisa e extensão. Enfim, desafios de expansão, equidade e qualidade, transversados pela internacionalização.

Nesse contexto, as questões aqui apontadas, e que incidem sobre a União Europeia, refletem também sobre os países emergentes que enfrentam grandes tensões entre uma concepção de universidade tradicional e uma concepção de universidade voltada ao século XXI, na qual o mercado orienta as concepções e ações. E, entre esses modelos, o contexto de transição coloca em destaque a questão da equidade. Portanto, o conceito de equidade entendido como "tratar diferentes de forma diferente" necessita ser ampliado para assegurar que esse tratamento forme um indivíduo com os mesmos atributos de outros que não necessitaram de tratamento "compensatório". Essa postura se aloca além da garantia de acesso e da permanência de pessoas ‘a educação superior; ela está intimamente atrelada ao direito à educação que, por sua vez, abarca a qualidade da formação. Assim, a concepção e prática de IoC tem um papel imprescindível a desempenhar para a qualidade da educação superior com equidade.

\section{REFERÊNCIAS}

BALL, S. Educação Global S.A.: novas redes políticas e o imaginário neoliberal. Ponta Grossa: UEPG, 2014.

BALL, S. Performatividade e Fabricação na Economia Educacional: rumo a uma sociedade performatividade. Educação \& Realidade, Porto Alegre, v. 35, n. 2, p. 37-55 maio/ago. 2010. Disponível em: <http://www.redalyc.org/articulo. oa? id=317227077004>. Acesso em: 20 dez. 2016

BENNETT, M. Transformative training: Designing programs for culture learning. In: MOODIAN, M. A. (Ed.). Contemporary leadership and intercultural competence: Understanding and utilizing cultural diversity to build successful organization. USA: Sage, 2008. 
CLIFFORD V. The elusive concept of the curriculum. 2013. Disponível em: $<$ https://www.brookes.ac.uk/services/cci/definitions.html>. Acesso em: 10 out. 2016.

CROWTHER, P. et al. Internationalisation at Home: A Position Paper. Amsterdam: EAIE, 2000.

DALE, R. Constructing risk manegement of HE sector through reputational risk manegement of institution. In: MOROSINI. M. (Org.). Quality in Higher Education: reflections and investigative practices. Porto Alegre: EdiPUCRS, 2011. (Série Qualidade da Educação Superior)

EGRON-POLAK, E.; HUDSON, R. Internationalization of higher education: Growing expectations, fundamentals values. IAU $4^{\circ}$ Global Survey, 2014. Disponível em: <www.iau-iau.net/all/filles/finaalorder form 4thGlobal survey.doc $>$. Acesso em: 08 nov. 2016.

FORMICHELLA, M. Índice de inequidad educativa básica: Una propuesta de medición de la Equidad Educativa Interna en Latinoamérica. Archivos Analíticos de Políticas Educativas, Arizona, v. 22, p. 1-23, jan. 2014.

FREEMAN, et al. Embedding the development of intercultural competence in Business Education ALTC funded project. Relatório: 2009. The University of Sydney, Australia: 2008.

HENAR, F. Aprendamos la lección: un repaso a la calidad de la enseñanza en la educación superior. OECD/IMHE: 2010. Disponível em: <https://www.oecd.org/ edu/imhe/47521693.pdf>. Acesso em: 14 dez. 2016.

HIGHER EDUCATION ACADEMY. Transforming teaching inspiring learning. Disponível em: <https://www.international.heacademy.ac.uk/services/Teaching-Excellence-Trio-Workshops>. Acesso em: 12 nov. 2016.

LEASK, B. Internationalizing the Curriculum. Routledge: New York, 2015.

LEASK, B. Using formal and informal curricula to improve interactions between home and international students. Journal of Studies in International Education, v. 13, n. 2, p. 205-221, 2009.

MOROSINI, M. (Ed.). Enciclopédia de Pedagogia universitária. Brasília, DF: INEP/MEC, 2006.

MOROSINI, M. Estado de conhecimento e questões do campo científico. Revista Educação. Santa Maria, v. 40, n. 1, p. 101-116, jan./abr. 2015. 
MOROSINI, M. Qualidade da Educação Superior e contextos emergentes. Avaliação. Campinas, v. 19, n. 2, p. 385-405, jul. 2014.

MOROSINI, M.; USTARROZ, E. Impactos da internacionalização universitária na docência universitária: construindo a cidadania global através do currículo internacionalizado e das competências interculturais. Em Aberto, Brasília, DF, v. 29, n. 97 , p. 35-46, 2016.

MOROSINI, M. C.; DALLA CORTE, M. G.; ANSELMO, A. Internationalization of higher education: perspective from the great South. Creative Education, v. 8, i. 1, p. 95-113, Jan. 2017.

NILSSON, B. Internationalising the curriculum. In: CROWTHER, P. et al. Internationalisation at Home: A Position Paper. Amsterdam: EAIE, 2000.

OECD. Teachers Matter: Attracting, Developing and Retaining Effective Teachers. 2005. Disponível em: <www.oecd.org/edu/teacherpolicy>. Acesso em: 05 dez. 2016.

OECD. Overview tertiary education for the knowledge society. 2008. Disponível em: https://www.oecd.org/education/skills-beyond-school/40345176.pdf>. Acesso em: 05 dez. 2016.

REFLEX. The Flexible Professional in the Knowledge Society: New Challenges for Higher Education. Project. European Union, 2011.

TEEKENS, H. Teaching and learning in the international classroom. In: CROWTHER, P. et al. Internationalisation at Home: A Position Paper. Amsterdam: EAIE, 2000.

UNESCO. Educação para a cidadania global (ECG): A abordagem da UNESCO, 2015. Disponível em: <http://www.unesco.org/new/fileadmin/MULTIMEDIA/ FIELD/Brasilia/pdf/brz_ed_global_citizenchip_brochure_pt_2015.pdf $>$. Acesso em: 11 nov. 2016.

UNESCO. Educação para a cidadania mundial: preparando estudantes para o século XXI. Brasília: UNESCO, 2015.

UNESCO. Education 2030 Incheon Declaration and Framework for Action: towards inclusive and equitable quality education and lifelong learning for all. Brasília: UNESCO, 2016. Disponível em: <http://www.unesco.org/new/pt/brasilia/ about-this-office/single-view/news/education_2030_incheon_declaration_and_and_ framework_for_ac/>. Acesso em: 14 dez. 2016. 
UNITED NATIONS. Understanding Knowledge Societies - Twenty answers and questions with the index of knowledge societies. Washington: United Nations, 2005 Disponível em: <https://publicadministration.un.org/publications/content/ PDFs/E-Library\%20Archives/2005\%20Understanding\%20Knowledge\%20Societies. pdf>. Acesso em: 14 dez. 2016.

VAN DER WENDE, M. C. Internationalising the Curriculum. Internationalisation of Higher Education. OECD Documents, 1996.

Recebido em: 07 de março de 2017 Aceito em: 11 de julho de 2017

Endereço para correspondência: Avenida Ipiranga, 6681, Partenon, 90619-900, Porto Alegre, Rio Grande do Sul; mariliamorosini@hotmail.com 
